\title{
表面移動法によるフラップ表面の剝離流制御*1 Control of Separation Flow on Flap by Moving Surface Method
}

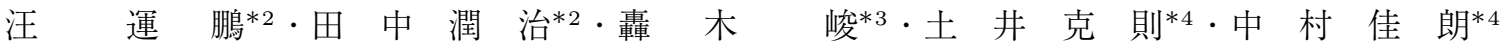 \\ Yunpeng Wang, Jyunji TANAKa, Takeshi Todoroki, Katsunori DoI and Yoshiaki NAKamura
}

Key Words : Flow Control, Separation Flow, High Lift Device, Moving Surface, CFD

\begin{abstract}
The moving surface method based on Quette Flow-type momentum addition was proposed as a new flow separation control method in order to suppress the flow separation over a flap at high attack angles and make lift enhancement. The effectiveness of the proposed method as well as the mechanism for suppressing the separation was studied by numerical simulations and experimental measurements in this study. The numerical results show that the moving surface works well to suppress the flap flow separation, so that lift coefficient can be increased significantly. In addition, the moving surface decreases pressure not only in the original separated flow region, but also in the leading edge region. Furthermore, the experimental result agrees with the numerical one in the case of a lower Mach number, which can validate the numerical results. Thus, the moving surface method proposed here is a promising method for controlling the flow separation over the flap.
\end{abstract}

\section{1. 序論}

航空機にとって重要な離陸・着陸性能や最大積載量は, 主 に高揚力装置の性能によって決定される。高揚力装置の性 能を向上させる手段の一つとして, 剝離を抑制する多段フ ラップが用いられているが, 機構が複雑で重量もかさむ. し たがって, 多段フラップに代わる, 簡単な構造で高性能な 高揚力装置が望まれている.

例えば, NASA は, 超短距離離着陸機 (ESTOL: Extreme Short Takeoff and Landing）の開発において, コ アンダ効果を利用した循環制御翼 (Circulation Control Wing）の研究を進めている1). なお, ESTOL は, 短距離 での離着陸による空港周辺の騒音低減も期待される。また, 欧州では, AWIATOR プログラムにおいて, 境界層厚さ よりも小さい渦発生装置 (SBVG: Sub-Boundary Layer Vortex Generator）をフラップに取り付けて剝離を抑制す る方法が研究されており, 風洞試験だけでなく飛行試験も 実施されている21.

高揚力装置の性能向上手段の一つは, フラップ角を大き くすることであるが，その場合フラップ上面で剝離を抑制す る手段である剝離制御 3 ) が必要となる、剝離制御の古典的な 方法は渦発生装置による方法 ${ }^{2,4)}$ であり, 発生した縦渦が混 合を促進し, 境界層外側の大きな運動量を壁付近に引き込 むことで剥離を遅らせる。 また，合成ジェット（Synthetic Jet）を用いて流れの混合を促進する方法 ${ }^{5 \sim 7)}$ も提案されて

\footnotetext{
*1 C 2010 日本航空宇宙学会

平成 22 年 2 月 9 日原稿受付

*2 名古屋大学大学院工学研究科

*3 川崎重工業株式会社

$* 4$ 名古屋大学工学部
}

おり, 噴出しや吸込みの周波数が剥離せん断層の最も不安 定な周波数に一致したときに効果が発揮される。ささらに，プ ラズマアクチュエータを用いて境界層に運動量を与える方 法8)も研究されている.

一方, デル夕翼の剝離制御として, 東ら ${ }^{9)} は$, 翼前縁の 表面を接線方向に周期運動させることで翼面上の渦を復活 させて揚力を得る方法を提案している. この効果は大きく, 失速時において約 $50 \%$ の揚力増加が得られる.

本研究では, フラップの剝離制御に表面移動法（Moving Surface Method）を適用する。表面移動法は, 物体表面を それに平行な方向に移動させて表面付近の流れを制御する 方法であり, クウェット流れの原理に基づく，すなわち，せ ん断応力の作用を介して, 境界層に直接的に運動量を付加 する方法である。この方法は, 剝離制御法として十分な効 果が期待される。

具体的には，母翼に単一のスロット付きフラップ (Slotted Flap）を付加した単純な翼構成を本研究の対象とし, その フラップ翼表面を一定の速度で平行な方向に動かすことに より剝離を制御する方法を提案する。そして, その効果を 数值シミュレーションによって評価する。 また, 風洞を用 いた実験を行い, その結果によってシミュレーション結果 の妥当性を示す。

\section{2. 計 算 対 象}

本研究では，母翼に単一のスロット付きフラップを付加 した単純な翼構成を対象とする。その翼形状を第 1 図に示 す．これは，NASA で開発された超臨界翼 (Supercritical Wing) 10）を基本形状とし，その翼後縁付近の形状を変更 すると共にスロット付きフラップを付加することで形成さ れる. フラップの翼弦長 $C_{\text {flap }}$ は, 基本形状の翼弦長 $C$ の 


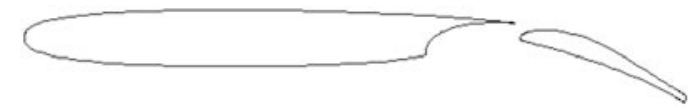

第 1 図 翼形状 $\left(\delta=20^{\circ}\right)$

第 1 表 計算対象の各条件

\begin{tabular}{lccc}
\hline & ケース 1 & ケース 2 & ケース 3 \\
\hline 基本翼弦長 $C[\mathrm{~m}]$ & 0.610 & 0.610 & 0.305 \\
フラップ角 $\delta[\mathrm{deg}]$ & 20 & 40 & 20 \\
母翼迎角 $\alpha[\mathrm{deg}]$ & 0 & 0 & 0 \\
一様流マッハ数 $M_{\infty}$ & 0.20 & 0.20 & 0.0088 \\
レイノルズ数 $R e$ & $2.8 \times 10^{6}$ & $2.8 \times 10^{6}$ & $6.1 \times 10^{4}$ \\
\hline
\end{tabular}

$30 \%$ とする.

本研究の対象とする各条件について, 翼形状の諸元およ び一様流の条件を第 1 表に示す. ケース 1 およびケース 2 の条件は Omar ら ${ }^{10)}$ の実験条件と同一であり, ケース 3 は 後述の実験条件と同一である. な招, 第 1 図に示す翼形状 のフラップ角は $20^{\circ}$ である.

\section{3. 計 算 方 法}

流体の支配方程式は圧縮性 Navier-Stokes 方程式とし, これを有限体積法で解く。非粘性流束の計算には, ケース 1 抢よびケース 2 では Roe の近似 Riemann 解法, ケース 3 ではSLAU 法 ${ }^{11)}$ を用いる。 なお，七ル境界での物理量は Van Albada の制限関数を加えた MUSCL 法により決定さ れる. 粘性流束の計算には中心差分法を用い, 時間積分に は 2 次精度の LU-SGS 法を用いる。また, ケース 1 およ びケース 2 では, 乱流モデルとして Baldwin-Lomax モデ ル12）導入する.

計算領域は 2 次元とし, マルチブロック法により計算格 子を形成する。フラップ角が 20 度である場合の計算格子の 一部を第 2 図に示す。このときのブロック数は 19 , 総格子 点数は 132,000 である.

\section{4. 計 算 結 果}

本節では, ケース 1 およびケース 2 の計算結果に基づき, 表面移動法による剝離制御の効果について述べる。

4.1 フラップ表面静止時の流れ場 初めに, 剝離制御を 行わない場合，すなわちフラップの翼表面を静止させた場 合に打けるフラップ上面の剝離流れについて述べる.

ケース 1 (フラップ角 $\left.\delta=20^{\circ}\right)$ およびケース $2\left(\delta=40^{\circ}\right)$ の表面静止時に扔けるフラップ周りの流線を第 3 図に示す. 母翼上面の後縁からの流れと翼下面からスロットを通り抜 けた流れがフラップ上面に到達する。このとき，フラップ 角が大きいケース 2 では, フラップ上面の流れが翼の途中 で剥離し，大きな渦を形成する。

また，同じ場合における母翼およびフラップ表面での圧 力係数分布を第 4 図に曲線で示す．ケース $2\left(\delta=40^{\circ}\right)$ の 場合には, フラップ上面の途中から後縁にわたって, 負圧が 小さく一様な值を示す、これは剝離による影響である。し たがって, フラップ上面での剝離を防ぐ，または，遅らせ

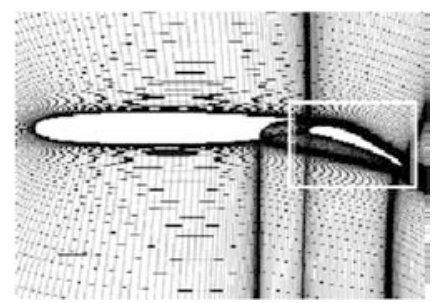

(a) 翼周り

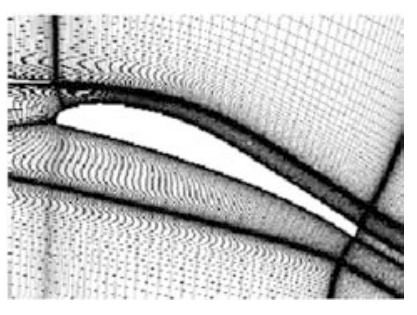

(b) フラップ周り
第 2 図 計算格子 $\left(\delta=20^{\circ}\right)$

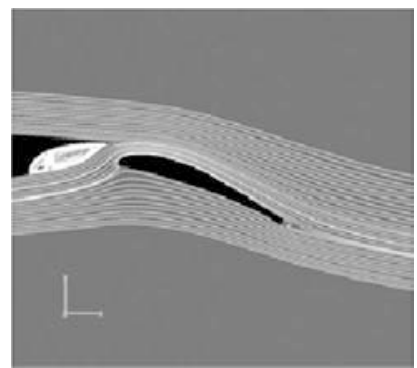

(a) ケース $1\left(\delta=20^{\circ}\right)$

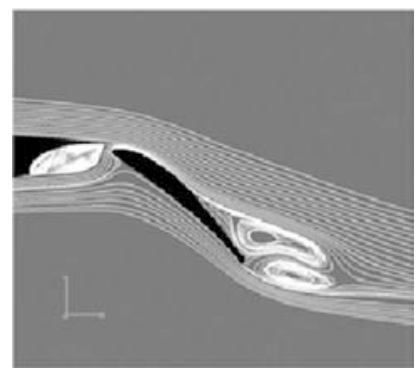

(b) ケース $2\left(\delta=40^{\circ}\right)$
第 3 図 フラップ周りの流線（表面静止時）

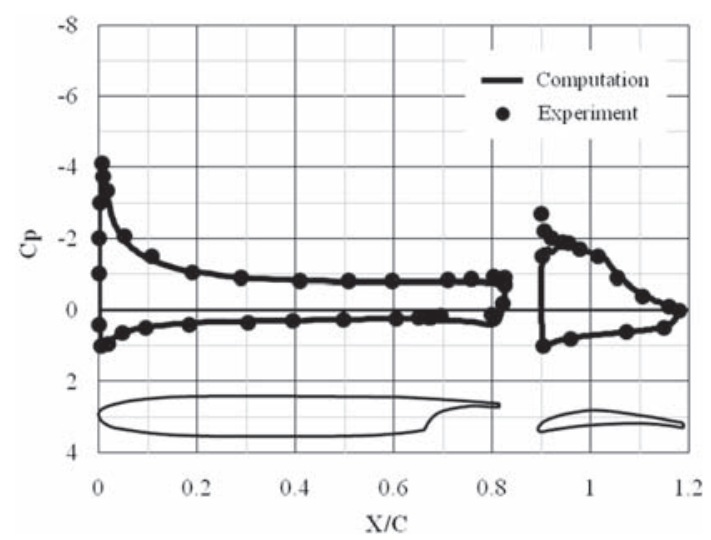

(a) ケース $1\left(\delta=20^{\circ}\right)$

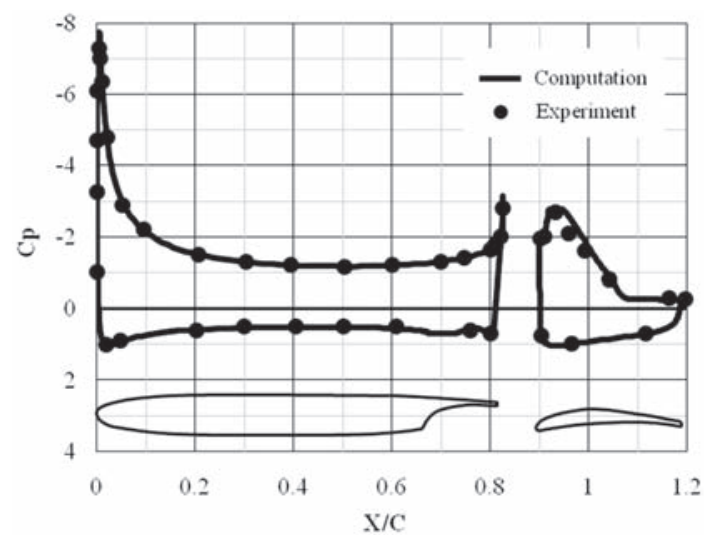

(b) ケース $2\left(\delta=40^{\circ}\right)$

第 4 図 母翼およびフラップの圧力係数分布（表面静止時）

ることで, フラップ上面での負圧が増加し，結果的に揚力 の増加を期待できる。

ケース 1 拈よびケース 2 と同じ条件での実験結果として, 


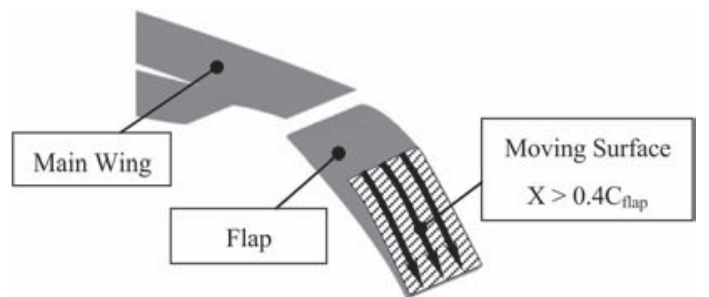

第 5 図 表面移動法の概要（ケース 2)

Omar ら 10) の結果を第 4 図に黒丸で併せて示す。実験結果 は, 本研究の計算結果とよく一致しており, 計算方法の妥 当性が確認できる.

4.2 表面移動法の導入 物体表面に沿う流れの剝離を抑 制するためには，流れを止めようとする逆圧力勾配に打ち 勝つだけの運動量を供給するのが一つの方法である。本研 究では, クウェット流れの原理に基づき, 流れと同じ方向 に物体表面を移動させることで, せん断応力の作用により 逆圧力勾配に打ち勝つ運動量を与える。すなわち, 翼表面 の一部を流れと同じ方向に一定の速度で動かす方法（表面 移動法）を採用する。

本研究では，表面移動法をケース $2\left(\delta=40^{\circ}\right)$ に適用す る。その概要を第 5 図に示す。フラップの前縁からの距離 $X$ とフラップ翼弦長 $C_{\text {flap }}$ の比が $X / C_{\text {flap }}=0.4$ である 位置を開始点として, 後縁までの範囲におけるフラップ上 面を，表面に沿って下流側へ一定の速度で動かす。なお， 表面静止時における剥離点の位置は， $X / C_{\text {flap }}=0.5$ であ る.

4.3 表面移動法による剥離制御の効果 ケース $2(\delta=$ $\left.40^{\circ}\right)$ において, 表面移動速度 $U_{\mathrm{w}}$ と一様流速度 $U_{\infty}$ の比が $U_{\mathrm{w}} / U_{\infty}=0.2, \quad 0.4, \quad 0.6, \quad 1.0$ であるときのフラップ周り の流線を第 6 図の (a), (b), (c), (d) にそれぞれ示す。第 3 図の (b) と第 6 図の (a), (b) を比較すると, フラップ上 面の移動速度が増加するにつれて, 剝離点は下流側へ移動 し, 剝離に伴って生じる渦も小さくなることが分かる。 そ して，第 6 図の (c) に示されるように， $U_{\mathrm{w}} / U_{\infty}=0.6$ ま で表面移動速度が増加すると, フラップ上面の流れは剝離 せず，表面に沿って後縁まで流れる。これは，表面移動法 による剝離制御が十分に可能であることを示す。ちなみに, 第 6 図の $(\mathrm{d})$ に示されるように, 表面移動速度をこれ以上 増加しても, 流線の様相はあまり変化しない.

$U_{\mathrm{w}} / U_{\infty}=0,0.2,0.4,0.6,1.0$ であるときのフラップ の圧力係数分布を第 7 図に示す. フラップ上面の圧力分布 について, 剝離点より上流側では一様な逆圧力勾配の領域 が存在し, 剝離点より下流側の圧力分布はほぼ一様である。 表面移動速度が増加すると, 剝離点は下流側に移動する。一 方, 剝離点より下流側の一様な負圧の大きさや上流側の逆 圧力勾配の大きさは表面移動速度の増加に対してあまり変 化しない。これらの結果として，フラップ上面での剝離点 より上流側のある位置における負圧は表面移動速度の増加 と共に大きくなる。 なお, 眓に示されるように, 剝離点が 後縁に達するまでの範囲において, 負圧の増加量は表面移

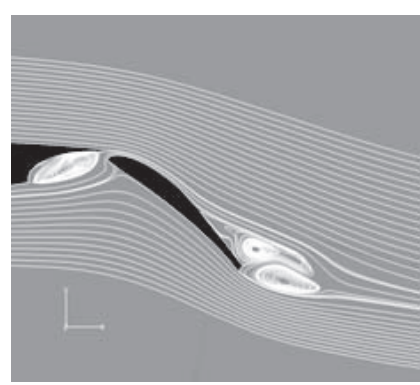

(a) $U_{\mathrm{w}} / U_{\infty}=0.2$

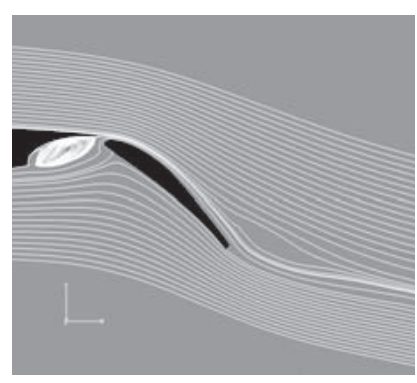

(c) $U_{\mathrm{w}} / U_{\infty}=0.6$
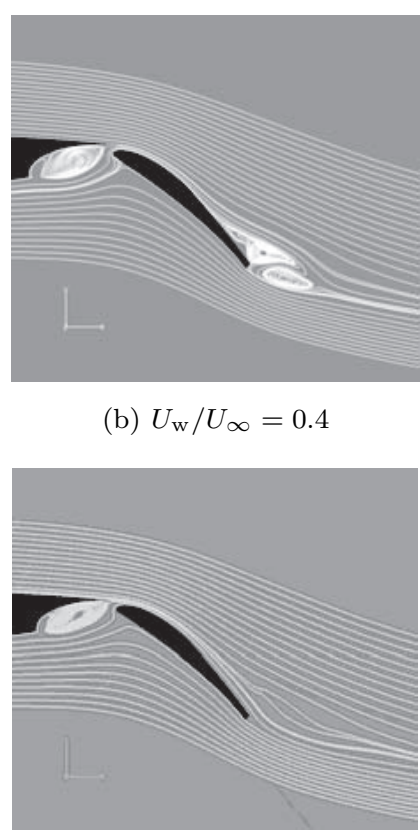

(d) $U_{\mathrm{w}} / U_{\infty}=1.0$ (b) $U_{\mathrm{w}} / U_{\infty}=0.4$

第6図フラップ周りの流線（ケース 2)

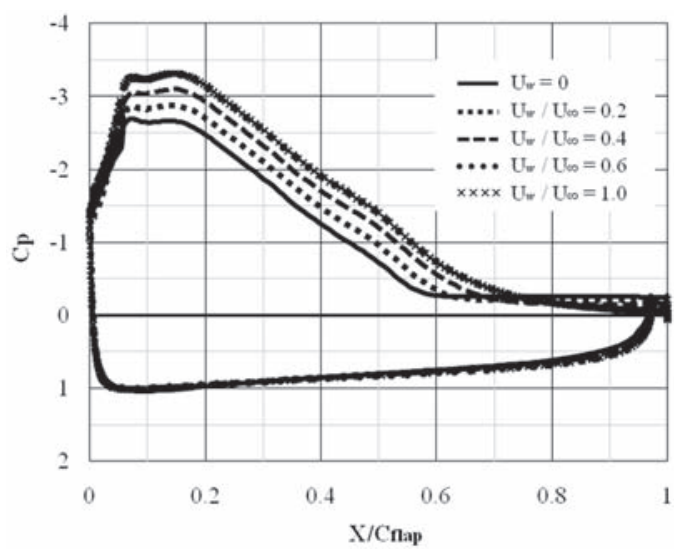

第 7 図 フラップの圧力係数分布（ケース 2)

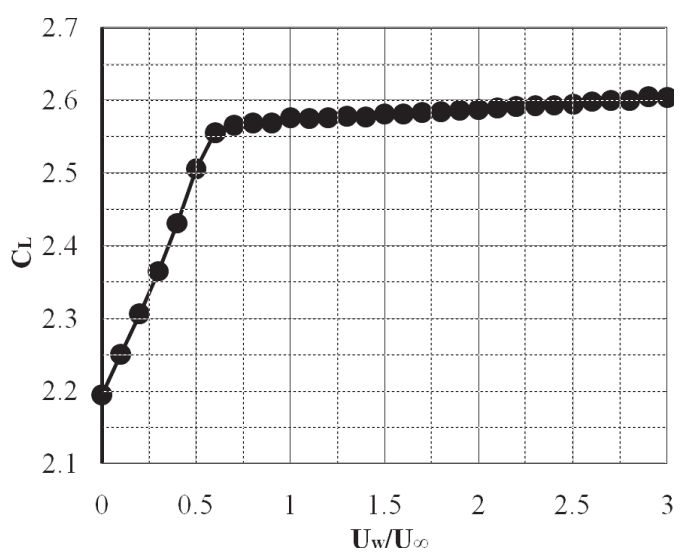

第 8 図＼cjkstart表面移動速度による揚力係数の変化（ケース 2)

動速度にほぼ比例する。

表面移動速度 $U_{\mathrm{w}}$ と揚力係数 $C_{L}$ の関係を第 8 図に示す. 


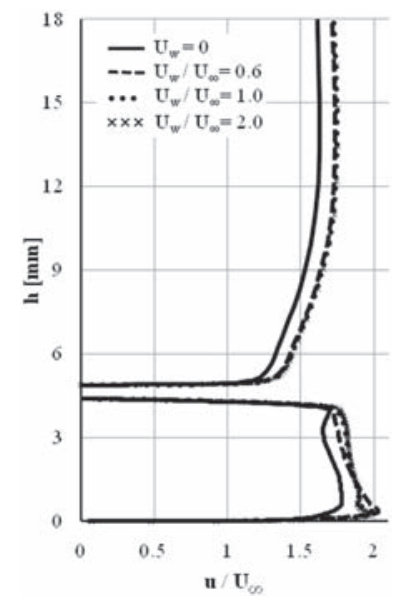

(a) スロット出口 $\left(X / C_{\text {flap }}=0.05\right)$

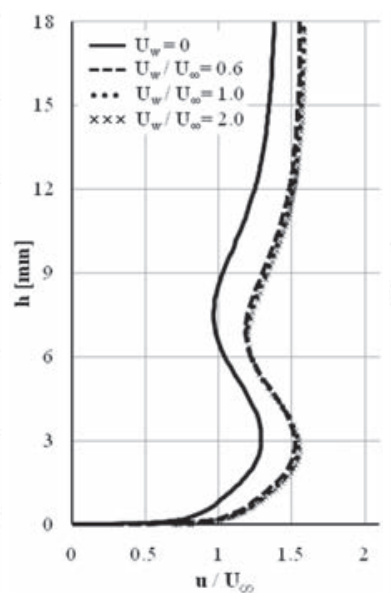

(b) $X / C_{\text {flap }}=0.4$

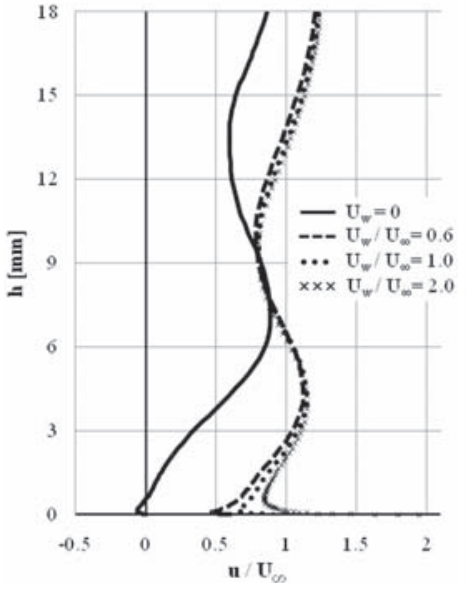

(c) $X / C_{\text {flap }}=0.6$

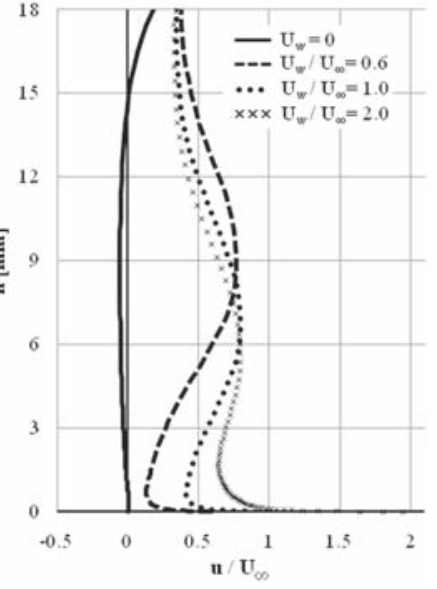

(d) $X / C_{\text {flap }}=0.8$

第 9 図 フラップ上面近傍の速度分布（ケース 2)

揚力係数は, フラップ上面の剝離点が後縁に達する表面移 動速度である $U_{\mathrm{w}} / U_{\infty}=0.6$ を閾值として, 特徵的な変化 を示す，表面移動速度が闇值以下である場合，フラップ上 面での剝離点の移動に伴う負圧の増加によって, 揚力は増 加する。 なお，負圧の増加量は表面移動速度にほぼ比例す るため, 揚力は表面移動速度にほほ比例する。一方, 表面 移動速度が閾值以上である場合, 翼周りの循環が付与され ることによって，揚力はさらに増加する。ただし，その増 加率は表面移動速度が閾值以下の場合に比べて小さい.こ のことは，表面移動速度が闇值以下の場合における揚力の 増加が主に剝離制御に依ることを示唆する。

表面移動速度が閯值 $U_{\mathrm{w}} / U_{\infty}=0.6$ であるとき，表面移 動法による剝離点移動の効果は上限に至る. 本研究の条件 における表面移動法の効果として, 揚力の増加量はフラッ プ表面静止時の揚力の約 $17 \%$ に達する.

4.4 表面移動法による循環付与の効果 フラップ上面 近傍の速度分布として, 表面移動速度が $U_{\mathrm{w}} / U_{\infty}=0,0.6$, $1.0,2.0$ であるときのスロット出口 $\left(X / C_{\text {flap }}=0.05\right)$, お よび $X / C_{\text {flap }}=0.4,0.6,0.8$ における表面に平行な速度 成分の垂直方向分布を第 9 図の (a), (b)，(c)，(d)にそれ ぞれ示す.

第 9 図 (a)において, $4.4 \leqq h \leqq 4.9$ に母翼の後縁が位置 し，その上側は母翼上面の流れを，その下側は母翼下面か らスロットを通過した流れを示す。そして，二つの流れは 合流し，第 9 図 (b) に示すように，極小点を挟んで二つの 高速域が存在する速度分布となる。剝離制御は，表面近傍 の流れに運動量を供給して, スロットを通過した流れに起 因する高速域の流れの剝離を防ぐ. 第 9 図の (c)や (d) を 見ると, $U_{\mathrm{w}}=0$ における逆流域が $U_{\mathrm{w}} / U_{\infty} \geqq 0.6$ では存 在しない, すなわち剝離が抑制されていることが分かる.

一方, $U_{\mathrm{w}} / U_{\infty} \geqq 0.6$ の範囲では, 表面移動速度の増加 による速度分布の変化は小さい. 第 9 図 (d) に示されるよ うに, 表面移動速度の増加と共に速度分布の極大点が表面 に近づくが, その極大值の増加量は小さい。すなわち, 翼

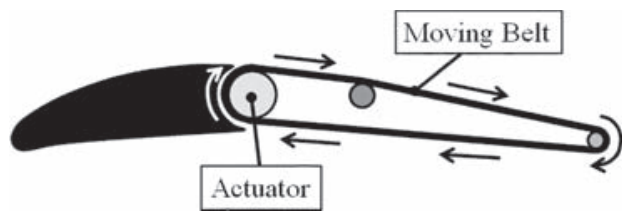

第 10 図 フラップ表面可動装置の概要

周りの循環の増加量も小さい. よって, 表面移動速度の増 加による循環付与の効果は小さい. 極大点の速度が増加し ない原因としては, 以下の二点が挙げられる。第一に, 運 動量を付加させるための粘性が比較的小さく, 表面移動速 度とその近傍の流速に大きな差が生じるため, 表面移動速 度が流れ場に影響しない. 第二に, 第 9 図 (a) に示される ように，表面移動速度が高くなるとスロットを通過する流 れの流量が飽和するため, フラップ表面に供給される流量 が制限され，極大点の速度も飽和する。このことは，スロッ トの開口面積を広くすることで, 表面移動法による循環付 加の効果が改善する可能性を示唆する.

\section{5. 実 験 方 法}

本研究では，上述の計算結果に基づく議論について，そ の妥当性を保証するために風洞による実験を行った.

本研究で用いたフラップ表面可動装置の概要を第 10 図に 示す，装置は，軟化ビニル製のベルトと，アクチュエータ としての電動モー夕を備え, モータでベルトを回転させる ことで表面移動法を実現する。なお，このような装置を用 いた結果, 前述の数值計算で考慮した条件とは異なり, フ ラップ下面では表面が上流側に移動する。また，表面移動 の開始位置は, フラップの翼弦長に対して前縁から $40 \%$ の 位置とし， $U_{\mathrm{w}} / U_{\infty}=0.5$ で移動させる。

実験条件はケース 3 とする。本条件は前述のケース 1 や ケース 2 に比べて低速である.

以上の実験装置および実験条件によって, 表面移動法を 適用した翼構成を模擬し, その流れ場を調べる。具体的に 


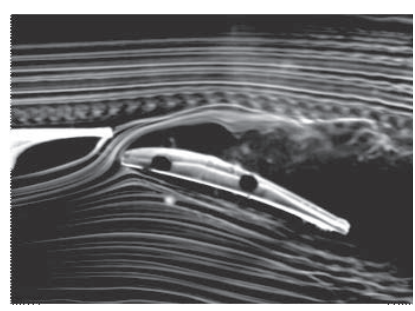

(a) $U_{\mathrm{w}}=0$

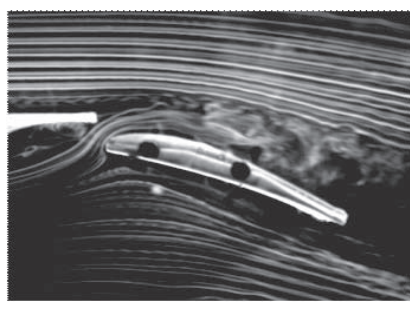

(b) $U_{\mathrm{w}} / U_{\infty}=0.5$
第11 図 Smoke-wire 法によるフラップ周り流れの可視化結果

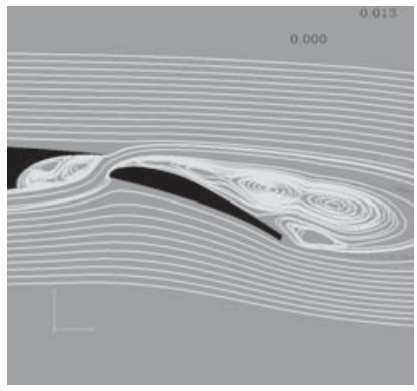

(a) $U_{\mathrm{w}}=0$

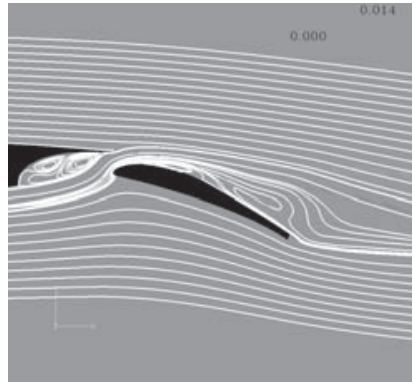

(b) $U_{\mathrm{w}} / U_{\infty}=0.5$
第 12 図 フラップ周りの流線（ケース 3）

は，Smoke-wire 法による流れの可視化，および，静圧管を 用いたフラップ表面圧力分布の計測を行う.

\section{6. 実 験 結 果}

ケース 3 に扔いて, フラップ表面静止時および移動時 $\left(U_{\mathrm{w}} / U_{\infty}=0.5\right)$ のフラップ周りの流れ場を Smoke-wire 法で可視化した結果を第 11 図に示す，表面静止時には母翼 下面側からスロットを通過した流れがフラップ上面の前縁 付近で大きく剝離するが，表面移動時には剝離が抑制され ている.

一方，同条件の計算結果におけるフラップ周りの流線を第 12 図に示す。な㧍, 本計算では, フラップ下面の $X / C_{\text {flap }} \geqq$ 0.4 の部分に打ける表面の速度を $U_{\mathrm{w}} / U_{\infty}=-0.5$ として, 実験と同様に下流側から上流側への移動速度を与える。実 駼結果と同様に，スロットを通過した流れの大きな剝離が 表面移動時には抑制されている。第 11 図の実験結果と第 12 図の計算結果を比較すると, 両者は定性的によく一致し ていることが分かる。

次に, 表面静止時および移動時 $\left(U_{\mathrm{w}} / U_{\infty}=0.5\right)$ におけ るフラップの圧力係数分布について, 計算結果を第 13 図に 曲線で示す。また，フラップ上面での各計測点における圧 力係数分布の実験值を同図に点で示す. 実験結果と計算結 果は共に，フラップ上面の上流側の負圧が表面移動時に逆 圧力勾配と共に増加する様子を示し，両者は定量的にもよ く一致していることが分かる.

以上の結果は，本研究に扔ける計算結果，および，その 計算結果に基づく表面移動法の評価を十分に保証する.

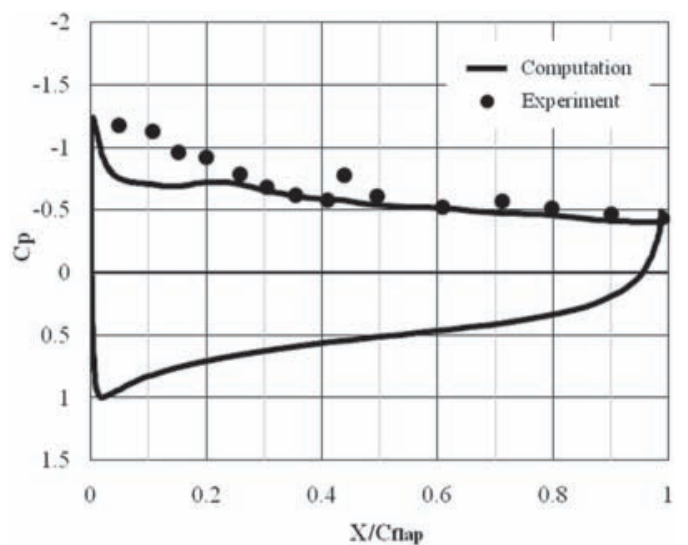

(a) $U_{\mathrm{w}}=0$

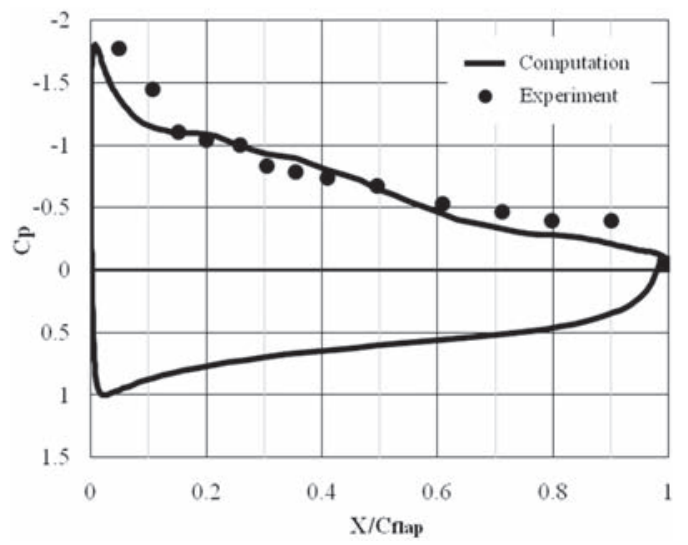

(b) $U_{\mathrm{w}} / U_{\infty}=0.5$

第13図 フラップの圧力係数分布（ケース 3)

7. 結論

表面移動法によるフラップ上面の剝離制御を提案し，そ の効果を数值計算によって評価した。 フラップ上面を流れ に沿う方向に動かすことで，剝離が抑制され，揚力は大き く増加する，揚力の増加量は表面の移動速度に比例し，剝 離点がフラップの後縁に達するまで大きく増加し続ける.

また, フラップ表面可動装置を用いた風洞試験を行い, 実 験に打いてもフラップ表面の移動による剝離の抑制効果拀 よび揚力増加を確認した。また, 実験結果と計算結果の一 致により, 計算結果の妥当性を示した。

本提案手法は簡単な原理に基づく方法であり, 高揚力装 置の性能向上手段として単純で確実な手法である。 また, 比 較的大きなエネルギー消費や重量増を伴うことが予想され る反面, 本研究の実験で用いた表面可動装置のような簡素 で古典的な構造で実現できるため, 低コストで高いロバス 卜性や信頼性が期待できる。したがって，本提案手法は高 揚力装置の性能向上手段として有意な手法である.

\section{参 考 文 献}

1) Jones, G. S., Yao, C.-S. and Allan, B. G.: Experimental Investigation of a 2D Supercritical Circulation-Control Airfoil Using Article Image Velocimetry, AIAA Paper 2006-3009, 2006. 
2) Bohannon, K. S.: Passive Flow Control on Civil Aircraft Flaps Using Sub-Boundary Layer Vortex Generators in the AWIATOR Programme, AIAA Paper 2006-2858, 2006.

3) Gad-el-Hak, M. and Bushnell, D. M.: Separation Control: Review, J. Fluids Eng., 113 (1991), pp. 5-30.

4) Lin, J. C., Robinson, S. K. and McGhee, R. J.: Separation Control on High-Lift Airfoils via Micro-Vortex Generators, J. Aircraft, 31 (1994), pp. 1317-1323.

5) Seifert, A. and Pack, L. G.: Oscillatory Control of Separation at High Reynolds Number, AIAA J., 37 (1999), pp. 1062-1071.

6) Melton, L. P. and Yao, C.-S.: Active Control of Separation from the Flap of a Supercritical Airfoil, AIAA J., 44 (2006), pp. $34-41$.

7) Tinapp, F. and Nitsche, W.: On Active Control of High-Lift Flow, Engineering Turbulence Modelling and Experiments 4,
Elsevier Science Ltd., 1999, pp. 619-626.

8) Post, M. L. and Corke, T. C.: Separation Control on High Angle of Attack Airfoil Using Plasma Actuators, AIAA J., 42 (2004), pp. 2177-2184.

9) 東 大輔, 中村佳朗 : 回転する前縁部によるデル夕翼の揚力増加, 日本航空宇宙学会論文集, 51 (2003), pp. 52-60.

10) Omar, E., Zierten, T., Habu, M., Szpiro, E. and Mabal, A.: Two-Dimensional Wind-Tunnel Tests of a NASA Supercritical Airfoil with Various High-Lift Systems, NASA CR-2215, 1973.

11) Shima, E. and Kitamura, K.: On New Simple LowDissipation Scheme of AUSM-Family for All Speeds, AIAA Paper 2009-136, 2009.

12) Baldwin, B. S. and Lomax, H.: Thin Layer Approximation and Algebraic Model for Separated Turbulent Flows, AIAA Paper 78-257, 1978. 